I Universidade Estadual de Campinas (Unicamp), Departamento de

Sociologia, Campinas, São Paulo, Brasil

rortiz@terra.com.br

https://orcid.org/oooo-0003-0246-5576

Renato Ortiz'

\title{
PEQUENA HOMENAGEM A UMA GRANDE SENHORA*
}

Quando era concierge em Paris, numa rua sem saída, apenas um quarteirão, logo ao lado do Jardim do Luxemburgo, sempre que saía de casa ou voltava, parava em frente a uma livraria que hoje não mais existe. Na época fazia meus estudos de graduação em Vincennes e praticamente desconhecia a geração de pensadores brasileiros que me antecedera. Tinha passado quatro anos na Escola Politécnica (USP), mas deixei o curso de engenharia no último ano e parti. As ciências sociais brasileiras me eram estranhas. Mesmo assim, sem a conhecer, parava em frente à vitrine para contemplar o livro exibido: Réforme et révolution dans les sociétés traditionnelles (Anthropos, I968). Uma sensação de orgulho me invadia - Maria Isaura Pereira de Queiroz (I9I8-20I8), brasileira, me contemplava do outro lado do vidro. A última vez que a vi foi em novembro de 2002 um pouco antes de ela sucumbir à doença do esquecimento. Conversamos e, generosa, presenteou-me com uma edição de I cangaceiros. I banditi d'onore brasiliani (Liguri Editori, I993). A conheci em francês e me despedi em italiano. O leitor pode se surpreender com a descrição de algo assim tão banal, mas ao direcionar dessa forma sua atenção, desde a abertura deste texto, tenho clara uma intenção: narrar minha pequena homenagem de um ponto de vista pouco usual. Sei que Maria Isaura fez toda sua carreira na FFLCH da USP, fundou o Centro de Estudos Rural e Urbano, deu aulas, orientou pesquisas e estudantes de pós-graduação. Sua vida entrelaça-se à cidade de São Paulo e à universidade na qual ingressou ainda em I946. Alguns textos que consultei, sobre a autora e sua obra, realçam esse aspecto. Entretanto, ao tomar como ponto de 
partida o exterior, o que se encontra lá fora, meu olhar quer deslocar uma certa narrativa que se faz sobre a história das ciências sociais brasileiras. Consigo assim retocar o retrato de uma grande senhora e, talvez, abrir uma pequena brecha nas interpretações consagradas em relação a nosso próprio passado.

Apesar da diferença de idade, quase 30 anos, tínhamos uma relação de amizade. Ao consultar seus livros na estante do escritório, nas dedicatórias de alguns deles está escrito: "com amizade constante e afetuosa" (Carnaval brésilien, Gallimard, I993); “com toda amizade” (edição italiana de Os cangaceiros). Ela, aliás, tinha participado da banca examinadora de minha livre-docência quando me presenteou com o livro que eu cobiçava na vitrine parisiense: "lembrança de uma velha livre-docência comemorando a sua, novíssima, e o abraço afetuoso" (Réforme et révolution"). Eu a visitava com certa frequência, telefonava e era convidado para um café. Em I977, quando estava na UFMG, pediu que eu organizasse o encontro do grupo de sociologia da cultura na reunião da Anpocs realizada em Belo Horizonte (a Anpocs foi fundada em 1976). Participamos juntos no seminário que organizei em Ouro Preto (“Cultura brasileira?") e vários dos textos que vieram a compor meu livro Cultura brasileira e identidade nacional foram primeiro publicados como artigos nos Cadernos do CERU, do qual ela era a editora principal. Maria Isaura não era uma pessoa de fácil convivência; tinha sido educada nos moldes tradicionais da elite paulista dos anos I920-I930. Esquece-se de que nessa hierárquica sociedade brasileira as relações entre professor e aluno, pais e filhos, homens e mulheres eram bastante formais, havia todo um código, bastante rígido (gestos, entonação da voz, Sr., Sra.), regendo a interação das pessoas. De alguma maneira tal formalidade se desfazia entre nós, talvez por causa da diferença de idade - minha geração tinha sido educada dentro de outros moldes. O trabalho intelectual nos unia, mas outros aspectos também nos aproximavam. Eu era um outsider, estrangeiro, não tinha cursado a USP; conhecia a história das disputas entre as cadeiras de sociologia I e II, os conflitos envolvendo o meio acadêmico paulistano, mas essas coisas eram indiferentes para mim. Tínhamos ainda dois pontos em comum: Paris e Roger Bastide. Maria Isaura dizia que seu pai era francófilo desde cedo a submergira na cultura francesa; em meados dos anos 30, ela saindo da adolescência, seu pai ganhou na loteria e foi com a mulher e as duas filhas a Paris. Ficaram vários meses em um hotel. Esse tipo de relato e de experiência me fascinava, lembrava os escritores "malditos" norte-americanos "exilados" nessa França pós-Grande Guerra. Ela retornou a Paris inúmeras vezes, numa época em que o deslocamento se fazia por navio (I5 dias de ida; I5 dias de volta); nos anos I950 fez seu doutorado sobre o messianismo do Contestado na École Pratique des Hautes Études. Seu livro Os cangaceiros (Queiroz, I977b) foi originalmente escrito em francês tendo sido publicado pela editora Julliard em I968 (a tradução para o português, feita pela autora, é bem posterior). 
Roger Bastide era também uma ponte entre nós; sua amizade e admiração pelo mestre era conhecida. No livro que preparou sobre sua obra para a coleção Grandes Cientistas Sociais (Queiroz, I983) posso ler na dedicatória de meu exemplar: "esta é uma lembrança dupla, não é? Com grande abraço afetuoso". As pessoas da geração dos anos I940/I950, quando se consolidam as ciências sociais no Brasil, eram cultas e eruditas, tiveram formação intelectual privilegiada, particularmente na cidade de São Paulo que se modernizava a passos céleres. Nessa época o horizonte de leitura dos cientistas sociais ampliou-se consideravelmente. Os textos da Escola de Chicago foram introduzidos entre nós pela Escola de Sociologia e Política, e as traduções em espanhol, vindas do México e da Argentina, colocavam à disposição dos leitores toda uma literatura de língua alemã. A missão francesa na USP, da qual Bastide fazia parte (permaneceu no Brasil de I937 a I954), era um polo ativo desse dinamismo intelectual. Maria Isaura iniciou sua trajetória acadêmica dentro desse ambiente, traduziu As regras do método sociológico, de Durkheim, e tinha o curioso hábito de fazer apostilas para oferecer a alunos e pesquisadores, como uma que me presenteou, com sua tradução de As classificações primitivas, de Durkheim e Mauss. Acredito, porém, que, no seu caso, isso não se restringe a um simples interesse pelos autores franceses; há algo mais: a incorporação de toda uma tradição, como em Bastide, que a fez aproximar as fronteiras disciplinares da sociologia e da antropologia. Seu interesse pela esfera da cultura fazia com que transitasse entre universos que, naquele momento, diante do processo de institucionalização das ciências sociais brasileiras, começavam a se separar.

Maria Isaura foi a mais importante socióloga que tivemos entre nós. Uma das poucas que conseguiram reconhecimento internacional com a tradução de seus livros para o francês, italiano e espanhol. No entanto, a afirmação que faço não se impõe enquanto tal. A velha senhora nunca conseguiu no Brasil o prestígio que merecia. Nos encontramos assim diante de uma espécie de esquecimento modelar pelos pares. Nem mesmo a literatura feminina ou feminista - que procura redefinir o papel das mulheres na sociedade e se contrapõe com outros olhos a uma versão da história que se solidificou - se interessou por seu destino. Esse esquecimento sistemático, inconsciente ou não, é problemático, distorce o passado e compromete o presente. Por que a considero importante? Certamente por causa de sua obra. A noção de obra implica uma totalidade, ou seja, a continuidade do trabalho intelectual. Nesse sentido difere da ideia de produtividade, atualmente vigente, quando se refere aos critérios, geralmente quantitativos, relativos à produção científica. A produtividade sublinha a particularidade de cada ponto descontínuo e por isso pode ser contabilizada em números. Quando me refiro à obra de um autor, ao contrário, importam antes a continuidade e a qualidade de seu trabalho. É preciso um esforço para que ela se prolongue no tempo e se realize em textos, livros ou artigos, que se articulem à sua totalidade. Uma obra se define ainda pela varie- 
dade de temas sobre os quais se debruça. No caso de Maria Isaura, seu labor criativo estende-se por vários anos; para se ter uma ideia, A Guerra Santa no Brasil: o movimento messiânico do Contestado é de I957, e o livro Carnaval brasileiro, de I992. O esforço intelectual cobre um extenso período de sua vida ativa. Mas é também pela variedade de temas abordados que sua obra se impõe: folclore, messianismo, religiões populares, mandonismo rural, campesinato, banditismo social, cultura brasileira (cf. Queiroz, I958, I973, I976). Seu interesse pela cultura popular considera tanto a dimensão do folclore, por exemplo, a dança de São Gonçalo, quanto uma manifestação nacional como o carnaval. Em suas pesquisas temos uma clara preocupação com a dimensão empírica, publicou, aliás, um opúsculo (Queiroz, I99I) sobre as variações técnicas do uso do gravador no registro das informações sociológicas, mas foi também ousada ao desenvolver projetos mais ambiciosos, como sua pesquisa original sobre o messianismo. O messianismo no Brasil e no mundo (Queiroz, I977a) é um belo estudo comparativo no qual a autora aborda o mesmo fenômeno social entre as tribos do oeste americano, na África, Melanésia, assim como em alguns movimentos do século XIX. Sublinho: quantos estudos comparativos desse porte existem nessa época no Brasil?

Maria Isaura era mulher em um mundo dominado por homens. Tinha clara consciência disso. Em nossas conversas deixava transparecer certo orgulho por suas origens, era sobrinha de Carlota Pereira de Queiroz, a primeira deputada mulher eleita para a Assembleia Constituinte em I934. É importante ter em mente que o Brasil dos anos I930-I950 era predominantemente masculino, inclusive junto à elite dominante. São poucos os exemplos de mulheres que se realizam plenamente e se impõem por seu próprio mérito diante de um quadro profundamente desfavorável. O espaço universitário não escapa a isso, a vida intelectual era uma prerrogativa masculina. Maria Isaura é a exceção que confirma a regra. Porém, quando se olha a tradição das ciências sociais no Brasil, em sociologia ou antropologia (a ciência política ainda não existia como disciplina entre nós), constata-se que sua estatura intelectual não apenas a distinguia de suas colegas mulheres como também era superior a muitos de seus colegas homens (por exemplo, Costa Pinto no Rio de Janeiro ou Thales de Azevedo na Bahia). Sua obra fala por si. Florestan Fernandes, colega e concorrente, por suas qualidades pessoais e grande capacidade de liderar um grupo dinâmico e criativo de jovens sociólogos, é talvez a única referência masculina que lhe pode fazer sombra. Como, entretanto, a narrativa sobre a história das ciências sociais no Brasil tomou como um de seus eixos de articulação a Escola de Sociologia da USP, uma dimensão feminina permaneceu olvidada. Sempre me intrigou como seria a vida dessas mulheres diante da situação inóspita à qual não podiam escapar. No caso de Maria Isaura talvez pudéssemos apontar dois tipos de estratégias que buscavam minorar tal condição de desigualdade estrutural. A primeira delas é de ordem pessoal, o fato de ter optado por não 
se casar. A recusa do lar, ou seja, do papel tradicional da mulher, permitiu-lhe mais oportunidades para construir seu próprio destino. Em termos sartrianos poderíamos dizer, sua liberdade privilegiou o caminho do "projeto" que acalentava. Outro aspecto diz respeito a sua trajetória no exterior (recordo-me de dois personagens importantes que conheci que faziam grandes elogios a sua obra: Michel De Certau e Eric Hobsbawm). Pode-se perguntar, pelo menos enquanto hipótese, se o circuito internacional no qual se movia não seria uma forma de compensar as restrições que conhecia em seu país natal. Se os caminhos aqui encontravam-se fechados, para sermos precisos, parcialmente fechados, o deslocamento para fora oferecia-lhe um horizonte mais aberto de realizações. Esse tipo de estratégia, entretanto, combinava dois elementos conflitantes, reconhecimento e restrição. Não é difícil identificar a dimensão relativa ao reconhecimento: seu livro publicado por Gallimard, uma das mais prestigiosas editoras francesas, ou seu círculo de amizades, Fernand Braudel, Lucien Febvre, Georges Balandier. ${ }^{\mathrm{I}}$ Mas havia também restrição nesse movimento de ampliação da circulação intelectual. Os anos I 940 e I 950 coincidem com a legitimação da sociologia brasileira como "ciência", ou seja, quando definitivamente se separa do ensaísmo de seus predecessores. O nacional é o espaço privilegiado de sua afirmação, e nesse sentido as fronteiras do reconhecimento são mais exíguas; o que se encontrava fora delas era importante, mas não decisivo.

A obra de Maria Isaura pode ser lida sob o signo da tradição, seus objetos de estudo assim o demonstram: messianismo, religiosidade popular (o trabalho sobre o padre Donizetti em Tambaú), folclore (dança de São Gonçalo na Bahia), campesinato brasileiro. Vários autores enfatizam essa dimensão; no entanto, a tradição não é percebida na sua imobilidade; pelo contrário, insere-se no quadro mais amplo das mudanças que marcam a sociedade brasileira (ver Botelho \& Carvalho, 20I I). Um exemplo: o coronelismo. Ele é simultaneamente fruto das transformações sociais e uma resposta a elas. O coronel é um oligarca que nas zonas rurais do Brasil deve adaptar o seu mando, fundado nas relações pessoais e na troca de favores com seu eleitorado, a uma situação de modernidade na qual o poder político se estrutura a partir de eleições generalizadas. Dito de outra forma, o "mandonismo" tradicional deve se adequar às mudanças impostas pela modernização do país. Pode-se dizer o mesmo em relação à cultura popular, ela se transforma mantendo uma certa "permanência" de seus traços. É interessante notar que Maria Isaura não se deixa seduzir pelos "estudos de comunidade" então em voga, ela não busca desenhar as fronteiras de uma identidade cultural particular (como os estudos de Antonio Candido em Bofete ou de Donald Pierson em Cruz das Almas). Pelo contrário, a tradição preservase em sua transformação. Em um plano mais geral pode-se dizer, ela não opera com a dicotomia tradição/modernidade. Esse é um caso relativamente raro na sociologia de seu tempo. A relação de antagonismo entre tradição e modernidade é a moeda corrente na maioria dos trabalhos que se fazem no 
Brasil e na América Latina. É preciso superar o "atraso" para que se possa, enfim, construir o projeto nacional almejado: ser moderno. Por fim, uma última consideração. Quando se lê uma obra desse tipo, para além do que está sendo dito, ela nos ensina sobre nossa própria história intelectual. Se nos países ocidentais (França, Inglaterra, Itália, Alemanha, Estados Unidos) a sociologia se funda a partir do entendimento de um determinado tipo de modernidade (industrialização, urbanização, burocratização etc.), entre nós os temas são outros: mestiçagem, mundo rural, cultos afro-brasileiros, cultura popular. Esses são os objetos privilegiados pelos precursores do pensamento sociológico (Nina Rodrigues, Sílvio Romero, Euclides da Cunha), temas que se prolongam, tratados agora de outra forma, nos trabalhos de sociólogos e antropólogos. Isso significa que a modernidade se realiza no Brasil de maneira distinta, e não "atrasada" como era percebida pela perspectiva eurocêntrica. Ou seja, a expansão da sociologia se faz levando em consideração os conceitos que a disciplina partilha e os contextos no qual se realiza. Como costumo dizer, a língua sociológica, comum àqueles que a praticam, só existe quando falada em seus diferentes sotaques.

Recebido em I/IO/20I9 | Aprovado em 7/I/2020

Renato Ortiz é professor titular do Departamento de Sociologia da Unicamp. Pesquisador IA do CNPQ. Doutor em sociologia/antropologia pela École des Hautes Études en

Sciences Sociales (Paris), é autor de diversos livros: A moderna tradição brasileira (I 988), Mundialização e cultura (I994), A diversidade dos sotaques: o inglês e as ciências sociais (2008), todos pela Brasiliense; Universalismo e diversidade

(Boitempo, 2016); O universo do luxo (Alameda, 2019). 


\section{NOTAS}

* Intervenção feita na mesa-redonda "Maria Isaura Pereira de Queiroz e o Trabalho Intelectual", I9 Congresso de Sociologia da Sociedade Brasileira de Sociologia, Florianópolis, julho 2019.

I Glaucia Villas Bôas (20I4) aponta para esse aspecto quando analisa sua relação com Bastide.

\section{REFERÊNCIAS BIBLIOGRÁFICAS}

Botelho, André \& Carvalho, Lucas.. (20II). A sociedade em movimento: dimensões da mudança na sociologia de Maria Isaura Pereira de Queiroz. Sociedade e Estado, 26/2.

Ortiz, Renato. (1985). Cultura brasileira e identidade nacional. São Paulo: Brasiliense.

Queiroz, Maria Isaura Pereira de. (I992). Carnaval brasileiro: o vivido e o mito. São Paulo: Brasiliense.

Queiroz, Maria Isaura Pereira de. (I99I). Variações sobre a técnica do gravador no registro da informação viva. São Paulo: T.A.Queiroz.

Queiroz, Maria Isaura Pereira de. (1983). Roger Bastide. São Paulo: Ática (Coleção Grandes Cientistas Sociais).

Queiroz, Maria Isaura Pereira de. (I977a). O messianismo no Brasil e no mundo. São Paulo: Alfa-Ômega.

Queiroz, Maria Isaura Pereira de. (I977b). Os cangaceiros. São Paulo: Duas Cidades.

Queiroz, Maria Isaura Pereira de. (I976). O mandonismo local na vida política brasileira. São Paulo: Alfa-Ômega.

Queiroz, Maria Isaura Pereira de. (I973). O campesinato brasileiro. Petrópolis: Vozes.

Queiroz, Maria Isaura Pereira de. (1958). Sociologia e folclore. São Paulo: Livraria Progresso.

Villas Bôas, Glaucia. (20I4). Amizade e memória: Maria Isaura Pereira de Queiroz e Roger Bastide. Lua Nova, 9I. 


\section{PEQUENA HOMENAGEM A UMA GRANDE SENHORA}

Resumo

Texto em homenagem a Maria Isaura Pereira de Queiroz. Diferentemente da maioria dos estudos sobre a história da sociologia brasileira, o autor toma a trajetória de Maria Isaura no exterior, principalmente a publicação de seus livros em outros idiomas, para entender determinados aspectos do campo intelectual nacional nas décadas de I950, I960 e I970. Situa ainda a autora, uma mulher excepcional, dentro das relações de gênero da época em que trabalha.

\section{HOMAGE TO A GREAT WOMAN}

Abstract

An article in homage to Maria Isaura Pereira de Queiroz. Diverging from the majority of studies on the history ofBrazilian Sociology, the author considers the intellectua trajectory of Maria Isaura from the perspective of how her writings were received abroad, beyond Brazil's intellectual frontiers. The publication of many of her books in foreign languages sheds light on various aspects of the Brazilian intellectual field in the I950s, 6os and 70s. The article also situates the author, a prominent woman of her time, within the context of gender relations during the period when she worked.
Palavras-chave

História das ideias;

teoria sociológica;

história das ciências sociais;

trajetória intelectual;

Maria Isaura Pereira de Queiroz.

\section{Keywords}

History of ideas;

sociological theory;

history of social sciences;

intelectual trajectory;

Maria Isaura Pereira de Queiroz. 